\title{
Dialética da ação em práticas pedagógicas: um processo pessoal e único de reconstrução racional pelo ator social
}

\section{Dialectic of the action in pedagogical practices: a personal and unique process of rational reconstruction by social actor}

\author{
Luiz Carlos Pereira Santos* \\ Daniela Venceslau Bitencourt**
}

\begin{abstract}
RESUMO
O objetivo deste artigo é investigar como a pesquisa-ação intervém, dentro da problemática evasiva da depredação e consumo em instituição pública. As ações aqui propostas foram desenvolvidas por 40 jovens entre 16 e 24 anos, acadêmicos do curso técnico de informática de uma escola púbica federal com a finalidade da racionalização de atividades dispendiosas, que ao longo do percurso acadêmico, nunca são apresentadas com corresponsáveis pelos danos causados. Para o desenvolvimento da pesquisa, foram utilizados: técnicas qualitativas e quantitativas como documentos, registros arquivados, entrevistas, observação direta e observação participante. Recorreu-se também à utilização de atividades no formato de grupos de estudo, aplicando as técnicas pedagógicas e distribuição de tarefas para organizar as relações entre os discentes e, com isso, desenvolver neles um conhecimento a respeito dos custos financeiros do patrimônio da escola. O que deixou claro que as atividades utilizando a pesquisa-ação atende a discentes com códigos, significados, representações, resistências, expectativas, a preservarem o bem público escolar em função de um método de trabalho científico.
\end{abstract}

Palavras-chave: Racionalização. Conscientização. Intervenção. Práticas educacionais. Pesquisa-ação.

* Instituto Federal de Sergipe. Programa de Pós-Graduação em Educação Profissional e Tecnonógico em Rede Nacional. Aracaju, Sergipe, Brasil. E-mail: luizcarlos.ifs@gmail.com. https:// orcid.org/0000-0001-7659-6144.

** Universidade Federal de Sergipe. Pesquisadora do Programa de Pós-Graduação em Desenvolvimento e Meio Ambiente (CNPQ/FAPITEC/UFS). Aracaju, Sergipe, Brasil. E-mail: daniela. aju@hotmail.com. https://orcid.org/0000-0002-6118-593X. 


\begin{abstract}
The aim of this paper is to investigate how action research intervenes, dentro da problemática evasivo da depredação e consumo em instituição pública. The actions proposed here were developed by 40 young people between 16 and 24 years, academic technician course of pubic school federal for the purpose of streamlining of costly activities that along the way, are never presented with the responsibility for damage. For the development of research, qualitative and quantitative techniques were used such as documents, archived records, interviews, direct observation, participant observation. Also was the use of activities in the form of study groups, applying the pedagogical techniques and distribution of tasks to organize the relationships between the students and develop in them a knowledge regarding financial costs the heritage school. The who checked of course activities using action research meets students with codes, meanings, representations, resistors, expectations, to preserve the public school on the basis of a scientific working method.
\end{abstract}

Keywords: Rationalization. Awareness. Intervention. Educational practices. Research-action.

\title{
Introdução
}

As políticas educacionais na atualidade estão permeadas pelo discurso da qualidade na educação, compreendida como cumprimento de metas preestabelecidas e auferidas a partir de mecanismos de avaliação externa. Inserir um aluno em um entendimento de que a escola é um bem público e, portanto, deve ser preservado, vai além do enfrentamento tantas vezes realizado por diretores, coordenadores pedagógicos e técnicos especialistas da educação, em seu confronto de como adotar ações da leitura e análise detalhada das depredações com os resultados, reunir a equipe para debater as informações obtidas e, com base no diagnóstico e nas reflexões realizadas, preparar um plano para transformar tudo isso em trabalho efetivo na escola.

Este trabalho ganha força com o Estatuto da Criança e do Adolescente (ECA), Lei $n^{\circ} 8.069 / 90$, no qual fala sobre o estudante que causar dano ao patrimônio público escolar, conforme seu art. 116:

Em se tratando de ato infracional com reflexos patrimoniais, a autoridade poderá determinar, se for o caso, que o adolescente restitua a coisa, pro- 
mova o ressarcimento do dano, ou, por outra forma, compense o prejuízo da vítima. (BRASIL, 2016, p. 30).

A intencionalidade neste debate, seria investigar uma escola pública federal profissionalizante, situada em um município denominado São Cristóvão, a 17 $\mathrm{km}$ da capital do estado de Sergipe, Aracaju, e refletir sobre sua essencialidade epistemológica, de que forma alunos assimilam que a sua escola possui custos (custo de energia elétrica, custos de água, custos quando se compra e se quebra, seja uma cadeira, uma mesa, uma lâmpada, etc). O presente trabalho aprofunda reflexões sobre a pertinência e as possibilidades da pesquisa-ação como instrumento pedagógico e científico, buscando indicativo de resposta à hipótese: Seria possível alunos numa cultura com códigos, significados, representações, resistências, expectativas, por certo variados e dissonantes, preservarem uma escola em função de um método de trabalho científico?

A pesquisa foi realizada no mês de março do ano de 2016, sendo finalizada em fevereiro de 2017, e recebeu financiamento da Pró-Reitoria de Pesquisa e Extensão a partir do edital de seleção para projetos para o Programa IFS Sustentável.

O texto está organizado em cinco partes. Num primeiro momento, apresentamos uma discussão sobre as proposições sociointeracionistas para as práticas de ensino, utilizando uso do método da pesquisa-ação. Em seguida, discute-se a relação dialética como instrumento para esse enfrentamento. Num terceiro momento, as práticas pedagógicas são avaliadas segundo a conduta discente em práticas pedagógicas. Logo em seguida, o discurso manifesta-se no papel metodológico da pesquisa-ação de remediar ações na percepção da valorização da escola pública. Em uma próxima etapa, o aluno é envolvido por ações práticas na condução de racionalizar e valorizar o patrimônio público.

\section{Proposições sociointeracionistas para o contexto da pesquisa}

Busca-se esse entendimento no método da pesquisa-ação educacional a partir do próprio surgimento de variedades distintas. Nesse sentido, é evidente que buscar formas de encontrar um eixo que atente para as vias da prática no ensino, seguindo-se uma perspectiva meritocrática do que seja o processo edu-

1 Instituto Federal de Sergipe. 
cativo, evidenciam-se formas experimentais de se buscar no trabalho científico um sentido da comprovação da hipótese.

Foi o que fez o psicólogo Stephen Maxwell Corey (1953), positivista que buscou formas de melhorar a prática docente e os resultados educativos. Sua proposta partiu da recognição de problemas na escola, formulando uma hipótese de intervenção praticada com os docentes no sentido de avaliar coletivamente as ações executadas. Percebeu-se que, nesse caso, o pesquisador tem um papel de investigador, mas os docentes não eram, na realidade, alçados à condição de pesquisador. Quando assim o faziam, mudavam suas ações e refletiam sobre os resultados.

Para o envolvimento dos docentes nesta pesquisa, busca-se no pensamento hegeliano do devir social de Lewin (1946, p. 46), a hipótese apresentada por ele de que "os fenômenos sociais não podem ser observados do exterior, do mesmo modo que não podem ser observados em laboratório, de modo estático".

Necessariamente, também na teoria do campo psicológico, formulada por Kurt Lewin, houve um propósito que veio a atender à formação dos alunos em práticas educacionais em virtude das variações individuais do comportamento humano, condicionadas pela tensão entre as percepções que os discentes têm de si mesmos e pelo ambiente psicológico em que se inserem, dentro do espaço escolar, onde se abrem novos caminhos para o estudo dos grupos de alunos.

A pesquisa-ação é essencial em transformação participativa, em que sujeitos e pesquisadores interagem na produção de novos conhecimentos, buscando constituir produções discentes com convicção de que pesquisa e ação podem e devem caminhar juntas quando se pretende a transformação da prática.

Com isso, o objetivo da pesquisa se traduz em investigar como a pesquisa-ação intervém, dentro de uma problemática que acontece diuturnamente dentro de uma escola técnica pública federal, em qual momento, o disperdício em razão do consumo e da depredação, que fazem parte do patrimônio escolar, não estão sujeitos a danificações imediatas. O que necessariamente se discute dentro da categoria freireana, o processo de formação de uma consciência crítica em relação aos fenômenos da realidade objetiva.

Nesse caso, recorrendo ao método da pesquisa-ação como remédio aos atores sociais, como intervenção, na procura de encontrar a racionalidade da causa, colocando como efeito uma metodologia estruturada de uma pedagogia fundamentada no estímulo da expressão individual na tomada de decisões.

Nesse modelo de intervenção, a pesquisa-ação aplicada à formação continuada de professores e discentes, evidencia a construção de um saber sobre si mesmo e sua prática profissional, a oferta de um trabalho de cuidado psíquico aos sujeitos participantes. Contudo, nem sempre os registros das observações são considerados na pesquisa e na formação de professores, uma vez que há 
uma verdadeira negação da existência dos conteúdos incongruentes que estimulam os alunos e que ultrapassam e afetam o seu querer consciente. Entende-se que a subjetividade dos participantes e a do pesquisador/mediador é uma dimensão fundamental da pesquisa-ação.

A justificativa para entender que a pesquisa-ação no campo da educação e, principalmente, para ser interposta em aula, pode justificar o seu uso e pode ser encontrada nas entrelinhas desenhadas pelo sociólogo Thiollent (1997, p. 36), quando formulada a partir do planejamento para a tomada de decisão, em que o autor diz que: "Requer, no mínimo, a definição de vários elementos: um agente (ou ator), um objeto sobre o qual se aplica a ação, um evento ou ato, um objetivo, um ou vários meios, um campo ou domínio delimitado".

Nesse segmento, estarão presentes como coadjuvantes o professor(a) orientador(a), conduzindo cada sequência e aplicação e os atores discentes, que carrearão o desenvolvimento do projeto, acrescentando seus objetos de pesquisas nos vários momentos do contexto da atividade pesquisada.

Nesse ínterim, postergar uma provocação à pesquisa-ação delineia no agente de mudança e de ator dialético um vínculo ocupado pelo pesquisador: "[...] constantemente a implicação e o distanciamento, a afetividade e a racionalidade, o simbólico e o imaginário, a mediação e o desafio, a autoformação e a heteroformação, a ciência e a arte." (BARBIER, 2002, p. 18).

Essa provocação à racionalidade de dentro do modelo educacional pode ser utilizada para subsidiar a análise de políticas públicas, o que, para Bardach (2012), representa uma abordagem epistemológica muito próxima da perspectiva racional. Isso pode ser refletido de forma que alunos entendam que o seu espaço escolar deve ser preservado; identifica proposições na formação discente em seu comprometimento com a escola em que estuda e em seu entendimento às relações de consumo, preservação e, principalmente, sustentabilidade, partindo para uma sensibilização de que seus atos vêm a "[...] lembrar que se caracterizam também pelas pichações, pela quebra de louças das instalações sanitárias, pelos furtos de lâmpadas e de outros materiais que se encontram instalados nas instituições." (CANDAU, 1999, p.29).

Permitirá ainda atingir atitudes norteadas pela ética, levando o discente a suprir as suas necessidades do presente, sem afetar a habilidade das gerações futuras de suprirem as próprias necessidades. E se, assim, não fosse conduzido, estaria se aproximando a filosofia do comportamento humano embrenhada no behaviorismo, desenvolvido pelo fundador psicólogo americano Burrhus Frederic Skinner. Segundo ele, o aluno é condicionado, a partir de motivações externas, a dar uma resposta, ignorando totalmente a consciência e os estados mentais.

$\mathrm{O}$ que se pretende nesse imediatismo é procurar por atividades que garantam mais transparência e reflexões para sensibilização dos alunos, perpassando 
por um construtivismo que gera uma relação sujeito e objeto para o ato de conhecer a partir do coletivo e, dessa forma, desenvolver um conhecimento para o seu mundo acadêmico.

Para isso, o sociointeracionismo, nascido da teoria de Vygostsky (1998), patrocina uma manifestação conjunta entre os acadêmicos, o que torna preeminente para esta pesquisa, visto que empreende que processos psicológicos surjam inicialmente nas relações sociais sob forma de convivência, passando ulteriormente para processos intrapessoais, como também individuais.

Para realizar as tarefas, foram desenvolvidas algumas atividades com os alunos, utilizando ferramentas que favorecessem aos discentes primeiramente, como foi o caso do conhecimento das medições dos custos da energia elétrica, água, seu consumo e cálculo. Os alunos aprenderam a anotar os valores diários de gasto da água e energia consumidas, e calcular o seu consumo e, com isso, assistir quanto a escola irá pagar. Em um segundo momento, foi provocado um entendimento de como se realizam os pregões para a aquisição de novos patrimônios para a escola quando acontece a sua depredação. Em seguida, foi proposto dividir os participantes da pesquisa constituída por 40 alunos participantes de forma voluntária, provenientes do curso técnico de informática, em número de sete grupos, com a intenção de anotar as reais depredações inseridas na escola por parte da comunidade escolar. Em uma última atividade, buscou-se nos discentes participantes de que forma se poderia racionalizar energia elétrica e água e resolver o problema da depredação do patrimônio escolar.

Mas no que dizer de uma escola pública federal em que todos os compromissos assumidos com as comunidades acadêmicas são cumpridos, o que não refuta que uma das causas da depredação escolar está relacionada à baixa qualidade de vida em termos de infraestrutura do ambiente das escolas públicas que se encontram no estado de abandono.

Mariana $^{2}$, aluna da escola, entre muitos que acabaram respondendo, fala sobre depredação:

Eu vi um colega depredando uma cadeira e ouvi quando ele disse que estava fazendo aquilo devido aos maus tratos que recebe em sua casa, o que acredito que não é na escola que devemos expressar as nossas mágoas, mas sei que a escola pode ajudar, ocupando o aluno em atividades que o torne útil. (Mariana, entrevista, 2016).

2 Nome fictício para reproduzir as falas dos alunos. 
Fruto das atividades desenvolvidas na pesquisa-ação, os alunos, por sua própria iniciativa, desenvolveram atividades de aviso sobre consumo de energia elétrica, água e o patrimônio da escola. Também realizaram visita às salas de outros cursos, notificando o problema e notificando aos alunos o quantitativo de cadeiras, mesas e paredes depreciadas ao longo de dois anos.

O que se alimenta, mesmo a pesquisa realizada na escola, sempre teve a parceria da direção, que se manteve solícita quanto a sua colaboração. Contudo a privação de documentos formais sobre casos de depredação do patrimônio escolar talvez comprove a pouca importância dada pela administração escolar ao vandalismo, às ações sobre essa prática, que são, na maior parte das vezes, punitivas e quase nunca preventivas.

Destarte, enfatiza-se que considerar a importância do respeito aos conhecimentos trazidos pelos alunos para a sala de aula, considerando-os como sujeitos produtores de cultura e agentes atuantes na transformação da sociedade, pode ir de encontro ao que Freire (2002, p. 70) entende por educação como prática da liberdade e se posiciona “ [...] ao contrário daquela que é prática da dominação, implica a negação do homem abstrato, isolado, solto, desligado do mundo, assim como também a negação do mundo como uma realidade ausente dos homens".

Dessa forma, inserir atitudes em discentes, que delineiam no conhecimento e desenvolvimento de seus talentos e individualidades, por meio da relação dialética teoria e prática, o que corroboramos com Freinet (1969, p. 85) em relação aos únicos conhecimentos que "podem influenciar o comportamento de um indivíduo são aqueles que ele descobre sozinho e dos quais se apropria".

\section{Relação dialética entre a teoria e a prática: alinhamento na prevenção}

Contudo acrescenta-se que, durante o acompanhamento dos alunos em suas inserções na busca de um entendimento discente para um acolhimento sobre os prejuízos na depredação e consumo, verificou-se que a relação teoria-prática estava, em verdade, pruduzindo uma relação dialética, ou seja, um vínculo na refutação e no enfrentamento. Nesse papel, a observação dialética será o instrumento considerado nas observações para esta pesquisa, que vem tencionando pontos-chave para um debate, por essa ser uma das problemáticas mais agudas tanto no campo das ciências como da filosofia.

E, nesse entendimento, a partir de um olhar discente, observa-se que essa inter-relação dialética se tornou importante, haja vista que não se deve conceber uma teoria separada da prática, o que podemos coadunar com Gramsci (2006), 
ao identificar que a filosofia da práxis é um projeto prático de construção de um mundo ou nova realidade.

Com isso, pode-se pactuar a relação teoria e prática quando depositado no Regulamento de Organização Didática (ROD) nos Institutos Federais, estando aprovado pelo Conselho Superior de cada instituição, e tem por objetivo tornar homogêneas as atividades acadêmicas em todos os campi e auxilia o funcionamento da administração institucional.

A unificação dos deveres dos discentes em cada unidade da federação praticamente é idêntica, pois segue um acompanhamento pelo Conselho Superior que assim identifica os deveres do grupo discente em sua estadia na escola. Um, entre muitas informações presentes na ROD, merece aqui uma atenção: é o de zelar pela manutenção da limpeza do local de estudo (salas de aula, laboratórios, oficinas) e demais dependências do campus, bem como materiais e equipamentos; é importante também saber que a escola obriga o discente indenizar os prejuízos quando causar danos à instituição ou a objetos de propriedade alheia.

Caso o aluno alegue que desconhecia esse dever, a ROD também alerta que o discente deve se manter informado, por meio da leitura de quadros de aviso, do site da instituição e dos demais instrumentos de divulgação no campus, o que garante o seu papel no alinhamento do saber discente quanto à prevenção do pretexto do aluno em negar que desconhecia seus direitos e deveres, pois a escola é provida de laboratório de informática e biblioteca com acesso à internet $\mathrm{e}$, com isso, ofererece os documentos necessários ao conhecimento dos direitos e deverer do aluno com a instituição.

\section{Produção do debate da conduta discente em práticas pedagógicas}

Com isso, as observações, durante um ano de pesquisa, demonstraram que o papel metodológico da pesquisa-ação consiste em tentar elucidar, de forma eficiente e eficaz, problemáticas as quais os métodos tradicionais efetivamente não conseguem contemplar.

Para a coleta de dados e análise dos resultados da pesquisa, foram utilizadas várias técnicas qualitativas e quantitativas, comumente utilizadas em pesquisa-ação, tais como: documentos, registros arquivados, entrevistas, observação direta, observação participante e artefatos produzidos para a execução do projeto.

Dessa forma, percebe-se que as atividades extracurriculares, tais como a iniciação científica, tornam-se um ato importante para a formação profissional e humana dos futuros técnicos profissionais quando incorporam a percepção 
do se fazer algo em prol da sustentabilidade. Isso porque, ao identificar, nesta pesquisa-ação, o comprometimento a partir do movimento dos participantes acadêmicos ao conhecimento de quanto se gasta em energia elétrica durante todo o desenvolvimento das atividades da pesquisa, os alunos acabaram informando que:

Ter ar-condicionado o tempo todo e lâmpadas acessas na mesma proporção induz aquilo que eles assistem nos meios de comunicação, o de se gastar com o intuito de se obter o conforto; há falta de informação dentro de casa e mesmo há não oportunização dentro da escola para este enfrentamento (Mariana, entrevista, 2017).

A necessidade na identificação pode gerar discentes motivados para a preservação do patrimônio escolar. Nesse sentido, Habermas (1982) absorve a perspectiva dialética a partir da introdução dos fundamentos da teoria crítica, o que estimula a melhoria na prática educativa docente. Na mesma proporção, Souza (2013) sugere que o espaço de transmissão de cultura e processos reitere o valor da conservação da memória da escola.

Vale ressaltar que, durante o ensino-aprendizagem com os participantes da pesquisa, foi realizado um momento de brincadeiras, no qual foi proposta a limpeza dos equipamentos do laboratório de informática e do laboratório de química. Essa situação, considerada imaginária, que foi realizada para os alunos pensarem sobre o tema "conservação", tornou-se bem aproveitada, uma vez que levou ao indivíduo a contribuir para o seu desenvolvimento, como propõe Vygotsky (1989) quanto à Zona de Desenvolvimento Proximal (ZDP). Com essa atividade o professor João ${ }^{3}$, ministrante de uma disciplina do curso de informática, comentou que:

Esse caminho percorrido pelos alunos nesta atividade da pequisa-ação, nos fez perceber o quanto a capacidade de realizar tarefas de forma independente, buscar os alunos a presenciarem um mundo reala acadêmico, e a sua capacidade de desempenhar tarefas com a ajuda dos professores ou colegas mais capazes, o fizeram compreender o quanto é importante adquirir uma dialética crítica. (João, entrevista, 2016).

3 Nome fictício para reproduzir as falas dos professores. 
Durante as atividades discentes na sua busca por inserir o seu conhecimento crítico, pôde-se perceber que, na busca por levar uma comunidade acadêmica a sua mais alta racionalidade com o erário público, consegue-se despertar a partir de ações e procedimentos assistidos por meio da pesquisa-ação uma conduta para a valorização da escola pública, a partir de um processo pessoal e único.

Essa viabilidade, a partir do processo pessoal e único, pode-se então contemplar Freire (1993), a partir do instante em que nos contornamos com a educação, invadimos um universo saturado de possibilidades, com amplo potencial transformador, no qual práticas podem estimular um processo educativo, fornecendo a emancipação dos envolvidos e, com isso, viabilizando a construção de um sujeito histórico e crítico de sua realidade.

\section{Um processo pessoal e único}

Percebe-se então que o educando é o sujeito da educação a partir das relações com o outro, com o objeto de conhecimento e o meio em que está inserido. Essa interação é imprescindível para que o discente se desenvolva e se torne sujeito de sua própria práxis.

Dessa forma, ao buscar contribuir com esse paradigma, os sujeitos se apresentam como rica fonte solidária, ficando bem estável a necessidade de sua participação em relação ao sentimento de pertencimento à escola e ao sentimento de responsabilidade pela depredação do patrimônio escolar.

Em uma primeira constatação, verificou-se que o valor pago, somado entre os mêses de março a maio de 2016, ficou na ordem de $\mathrm{R} \$ 15.378,67$. Esse custo foi rateado com três laboratórios de informática e oito salas de aula. Após as várias manifestações pela racionalidade na escola, foi realizada uma nova avaliação entre os meses de setembro a novembro, e os valores cairam para $\mathrm{R} \$ 14.578,32$. Uma redução em torno de $5 \%$ do valor da conta de energia da escola. Nessa redução está incluído, o modo de uso dos ares-condicionados de sala de aula e laboratórios de informática. A aluna Mariana assim registrou:

Os alunos aqui não são ruins, mas não estavam preparados para serem bem tratados, e ao colocar uma responsabilidade que cada um dos grupos participantes iria desenvolver, o resultado foi essa redução. De fato, os alunos estão de parabéms. Eu inclusive não acreditei que haveria redução na conta de energia, pois eles sempre deixavam ligados, esperando 
que o laboratório fosse desligado pelos professores, o que poderia não acontecer devido ao ato de confiança que os professores depositavam a quem solicitava o laboratório para estudar (Mariana, entrevista, 2016).

Quanto ao consumo de água, entre março a maio de 2016, foi observado que estava em torno de $\mathrm{R} \$ 5.235,34$. Ao refazer as avaliações de custo para a água nos meses de setembro a novembro, o valor ficou em média em $\mathrm{R} \$ 4.145,72$. Uma redução em torno de $20 \%$.

Em uma terceira etapa, focou-se nas cadeiras e carteiras, que, em número de depredação, entre os meses de março a maio, foi constatado uma quantidade de 12 cadeiras quebradas e nove mesas com defeito ${ }^{4}$, tornando-as sem utilidade para estudo em sala de aula. Assim, foram feitas novas avaliações entre os meses de setembro a novembro de 2016, vericando-se que havia apenas três cadeiras com defeito, mas, ainda com condições de uso, e apenas duas mesas depredadas. Uma redução em torno de $75 \%$. Em relação às mesas, pôde-se ser observada uma diminuição na ordem de 77\%. Mariana, assim, revelou que:

Eu mesmo vi com meus próprios olhos, quando um dos alunos que havia participado da pesquisa-ação realizada pelo pesquisador com a ajuda dos professores, quando via algo errado sendo feito em sala de aula, sem a presença dos professores, automaticamente, já buscava a atenção de um responsável da escola para checar e aconselhar o aluno a não realizar mais aquela atitude. Mesmo o aluno, dizendo que iria realizar depois a danificaçao da cadeira, os próprios colegas e muitos individualmente o alertaram informando as penalidades que isso poderia ocorrer. Contudo, ele não fez mais, não que agente soubesse. Não em nossa sala de aula. (Mariana, entrevista, 2016).

A pesquisa demonstrou que os discentes, de fato e de direito, pelo menos os que participaram da metologia da pesquisa-ação, ao participar como um sujeito crítico a ponto de perceber seus atos como necessários ao desenvolvimento de suas habilidades, o que podemos idealizar em Guy Brousseau, um dos pioneiros da didática da matemática Francesa, quando buscamos no aluno resposta inicial baseada em conhecimentos anteriores, percebemos que isso fará com que o discente responda parcialmente a questão. $\mathrm{O}$ que o autor chama a atenção para a forma como o desequilíbrio que impulsionará o aluno a buscar modificações na

4 "Com defeito" quer dizer arranhadas, com algum lado depredado. 
estratégia inicial a partir de acomodações em seu sistema de conhecimentos, onde as modificações provocadas pela situação serão o motor de sua aprendizagem. Sendo assim, Brousseau observa que: "Para o professor, é grande a tentação de pular estas duas fases e ensinar diretamente o saber como objeto cultural, evitando este duplo movimento. Neste caso, apresenta-se o saber e o aluno se apropria dele como puder." (BROUSSEAU, 1996, p. 49).

Dessa forma, reconheceu-se que o papel discente para uma aproximação de ser inserido como um ser que faz parte da escola, permiti-lo-á se antecipar a qualquer possibilidade de destruição do patrimônio público. Para tanto, o papel do professor é crucial, pois possibilitará que o aluno atue sobre a situação, sem interferência explícita, nem condução.

\section{Reconstrução racional pelo ator social}

Questiona-se que é um dever da escola, mais do que qualquer outra instituição, desenvolver em seus alunos atitudes da não acomodação e preservação do patrimônio público. No entanto, percebeu-se que, após os alunos terem participado das atividades metodológicas da pesquisa-ação, uma afirmação a essa atitude para uma racionalidade dialética passa por uma necessidade que a escola seja formativa e não apenas informativa. Dessa forma, Giacaglia e Penteado (2000) enfatizam que o professor, em sua orientação educacional, deve seguir um processo educativo que venha a medrar simultaneamente ao processo de ensino-aprendizagem.

Para uma busca em seu processo de reconstrução racional de um saber, observamos no discente que, após a constatação de um fato de depredação e as lutas diárias da escola para encontrar o autor, esse arrependimento parece que não se constituir apenas de mero contato com a família, ou mesmo uma punição. Concordando com Bourdieu (2005), ao entender que a base das estratégias de reprodução está no esforço das famílias como ser social - nas suas observações de comportamento de seus filhos e verificar o seu rendimento escolar, o que, na maioria do investimento na educação escolar, faz parte dessas estratégias.

Contudo, ao reproduzir uma cultura externa relevante ao discente, parece que de fato escola e família alcançam os seus objetivos agregados às atividades extracurriculares, como foi o caso da prática com a pesquisa-ação, em que os processos e técnicas desse método, produziram efeitos a partir das funções formuladas por Kurt Lewin (1946), ao qual chamou de: planejamento, coordenação, avaliação e assessoramento. Na perspectiva de orientar e alocar responsabili- 
dades discursivas na produção retórica do discente, o estudo verificou que o aluno passa por um processo na escola que permeou preparos individuais que oficializaram tomadas de decisões inteligentes, que buscaram ser reflexivos, críticos e participativos.

Contudo percebeu-se com esta pesquisa que o professor, nesse novo instituto, tornou-se um coordenador das tarefas, dos saberes distribuídos, sejam esses científicos e/ou do senso comum. O que venho a atender os princípios reflexivos da pesquisa-ação. Dessa forma, a própria pesquisa-ação tornou esse professor, além de um facilitador desse processo, um participante e um parceiro do que estava sendo proposto.

Tambem foi possível perceber que os discentes passam por um paradoxo. Ao repassar ao aluno um excesso de informações que são pouco úteis em seu processo de assimilação. Parece que não surtiu efeito em termos de oferecer ao discente, o compromisso da preservação identificada em sua conduta de práticas. Neste caso, ao aluno, o que parece, não visualiza o risco que está passando, ao depredar um patrimônico público.

Consequentemente, a escola é contornada por leis e regras que devem ser cumpridas. Aliás, Pérez Gómes (1992) salienta que esse fenômeno enraizado em uma perspectiva cultural, atende a uma função social da escola que é justamente o desenvolvimento do processo de socialização dos mais jovens, de acordo com os modos de pensar e agir das culturas adultas. O que, vivenciamos para a lógica discente, parece que o descaso da punição escolar se coaduna com a sua sensação simultânea de não pertencimento a um grupo social de referência, o que se vivencia no percurso da pesquisa com a sua necessidade de satisfações imediatas e o que nos alinha a uma vontade do indivíduo de uma representação, vivenciada por um ator em um mundo virtual, ou mesmo realista, encontrado em programas televisivos ou outro meio meritocrático.

Durante a coleta de informações para a produção escrita deste trabalho, vislubramos com algumas situações que já são comuns em quem escreve sobre a definição da situação dos conflitos no contorno da escola e que ajudou muito no entendimento deste trabalho, bem como os trabalhos de (Charlot, 2002; Debarbieux; Blaya, 2002; Capra, 1996; Gutiérrez, 1999; Morin; Moigne, 2013 e Triviños, 1987). Estes autores, vêm há muito tempo, corroborando os problemas escolares e sua complexidade no exercício do magistério no cenário contemporâneo, o que expõem as dificuldades dos profissionais da educação no enfrentamento das situações de conflito no espaço escolar. 


\section{Considerações finais}

Com a consumação da pesquisa, percebeu-se que a escola é um local precioso para o aluno descarregar suas vontades, e uma delas seria a depredação. Dessa forma, foi possível evidenciar a importância de uma abordagem baseada no método da pesquisa-ação, evidenciando uma dialética pautada em resultados na análise do comportamento discente, o que proporcionou entender esse aluno em seu estudo histórico, crítico e cultural, que permitiu nesta investigação uma compreensão de como a escola pode solucionar a partir de métodos, como o da pesquisa-ação.

Também foi possível perceber o quanto alunos desenvolverem práticas pedagógicas e colocarem-se em um papel de corresponsáveis pela gestão escolar evidenciou uma conduta de superação e, com isso, foi possível pautar no referencial dialético de investigação científica e perceber que a forma que os alunos melhor assimilam o custo financeiro para manter uma instituição de ensino está justamente em apresentar ao aluno os resultados dos custos financeiros, ou a partir de atividades extracurriculares ou a partir de dinâmicas de grupo que levem o aluno a desvendar a sua mais alta criticidade a partir de uma reconstrução racional desse ator social.

Sobre as mudanças de atitudes em relação ao papel dos alunos em demonstrar os resultados das depredações e custos de manutenção do patrimônio escolar, foi reconhecido que se faz necessário um processo educativo mais amplo, e percebeu-se que as concepções dos alunos após as atividades desenvolvidas a partir do método da pesquisa-ação evidenciam o início da implementação de uma educação, pautada na ética e nos bons costumes na escola. No caso da atividade de divulgação dos custos financeiros na manutenção do patrimônio da escola para os demais alunos que não participaram dessa atividade, aqueles que participaram procuraram as salas de aula, enquanto divulgadores, e isso foi determinante para que aflorassem vozes emitindo opiniões com o intuito de superar essa problemática.

Sobre as influências da pesquisa-ação nesta investigação, constatou-se que os professores (as) evidenciaram possuir influências diretas provenientes dessa metodologia de pesquisa, o que proporcionou, segundo eles (as), trabalharem melhor em grupo e em seu individualismo. Também se percebeu que relações possíveis entre a escola em seu contexto e as questões da realidade dos alunos, o saber ouví-lo, durante as atividades desenvolvidas, foi possível verificar que os professores (as) interagiram, interferiram, opinaram para uma melhor adaptação do seu aluno com o ambiente escolar. 
Dessa forma, conclui-se que a pesquisa-ação é um percurso relevante para investigações que buscam propiciar melhorias e mudanças nas relações de ensino e aprendizagem, por propiciar que as ações sejam idealizadas a partir das inevitabilidades individuais e coletivas, o que tornou possível alunos numa cultura com códigos, significados, representações, resistências, expectativas, por certo variados e dissonantes, preservarem uma escola em função de um método de trabalho científico.

\section{REFERÊNCIAS}

BARDACH, Eugene. A Practical Guide for Policy Analysis. 4. ed. London: Sage, 2012. BARBIER, R. A pesquisa-ação. Trad. Lucie Didio. Brasília: Líber Livro, 2002.

BRASIL. Código Civil e normas correlatas. Estatuto da Criança e do Adolescente. 7. ed. Brasília: Senado Federal, Coordenação de Edições Técnicas, 2016. Disponível em: <www.planalto.gov.br/ccivil_03/leis/18069.htm>. Acesso em: 04 maio 2016.

BRASIL. Ministério da Educação. Secretaria de Educação Profissional e Tecnológica. Instituto Federal de Sergipe. Regulamento da Organização Didática. Disponível em: $<$ http://www.ifs.edu.br/proen/images/Documentos/2016/CS_35_Aprova_a_reformulação_do_regulamento_da_Organização_Didática.pdf>. Acesso wm: 31 mar. 2016.

BROUSSEAU, Guy. Fundamentos e Métodos da Didáctica da Matemática. In: BRUN, J. Didática das Matemáticas. Tradução de: Maria José Figueiredo. Lisboa: Instituto Piaget, 1996.

BOURDIEU, P. Razões práticas: sobre a teoria da ação. Campinas: Papirus, 2005.

CANDAU, Vera Maria. Escola e Violência. Rio de Janeiro, 1999.

CAPRA, F. A teia da vida. São Paulo: Cultrix, 1996.

CHARLOT, Bernard. A violência na escola: como sociólogos franceses abordam essa questão. Porto Alegre: Sociologias, 2002.

COREY, S. M. Action research to improve school practices. Nova York: Teachers' College Press, 1953.

DEBARBIEUX, Eric; BLAYA, Catherine (Org.). Violência nas escolas e politicas públicas. Brasília, DF: Unesco, 2002.

GIACAGLIA, L. R. A.; PENTEADO, W. M. A. Orientação educacional na prática: princípios, técnicas, instrumentos. São Paulo, SP: Pioneira Educação, 2000. 
GRAMSCI, Antonio. Cadernos do Cárcere. Trad. Carlos Nelson Coutinho. Vol. 1. Rio de Janeiro: Civilização Brasileira 2006.

GUTIÉRREZ, F.; PRADO, C. Ecopedagogia e cidadania planetária. São Paulo: Cortez, 1999.

FREINET, C. O método natural. Trad. Franco de Sousa e Teresa Balté. Lisboa: Estampa, 1969. 2 Vols.

FREIRE, P. Pedagogia do oprimido. 22. ed. Rio de Janeiro: Paz e Terra, 1993.

FREIRE, P. Pedagogia dos sonhos possíveis. São Paulo: UNESP, 2002.

HABERMAS, J. Connaissance et intérêt. Paris: Gallimard, 1982.

LEWIN, K. Action research and minority problems. Journal of Social Issues, Malden, v. 2, n. 2, p. 34-36, 1946. Disponível em: <http://onlinelibrary.wiley.com/ doi/10.1111/j.1540-4560.1946.tb02295.x/full>. Acesso em: 14 mar. 2016.

MORIN, E.; MOIGNE, J. L. L. A inteligência da complexidade. Rio de Janeiro: Fundação Petrópolis, 2013.

PÉREZ GÓMEZ, A. I. O pensamento prático do professor - A formação do professor como prático reflexivo. In: NÓVOA, A. (Org.). Os professores e a sua formação. Lisboa: Dom Quixote, 1992.

SKINNER, B. F. Science and human behavior. New York, NY: The Free Press, 1965.

SOUZA, R. F. de. Preservação do patrimônio histórico escolar no Brasil: notas para um debate. Revista Linhas, Florianópolis, v. 14, n. 26, p. 199-221, 2013.

TRIVIÑOS, A. N. S. Introdução à pesquisa em ciências - a pesquisa qualitativa em educação: o positivismo, a fenomenologia e o marxismo. São Paulo: Atlas, 1987.

THIOLLENT, M. Pesquisa-ação nas organizações. São Paulo: Atlas, 1997.

VIGOTSKY, L. S. Pensamento e linguagem. São Paulo: Martins Fontes, 1989.

Texto recebido em 09 de abril de 2018.

Texto aprovado em 18 de maio de 2018. 